\title{
Nature, Scope and Role of Research Proposal in Scientific Investigations
}

\author{
Oguduvwe, Jonathan I. Pius \\ B.Sc, M.Sc Geography and Regional Planning, (Delsu, Abraka)
}

\begin{abstract}
Lack of good research proposal and its presentation is a growing concern in academics researches worldwide. This has been linked to increased poor research writing skills and unavailability of relevant materials including presentation and interpretations of researches. What makes a good research proposal and the basic ideas and steps of the research proposal in scientific investigations were lacking also. The nature, scope and role of research proposal was conceived with the mind to attempt to overcome this non-unique approaches into researches but from different disciplines by providing a-one-stop article for good research proposal writing and presentation. In order to get the above fulfilled, the concept and procedures of good research proposal writing were examined and explained. The basic steps and the importance of research proposal were equally outlined. Good examples were used in illustrations and recommendations were also advanced.
\end{abstract}

\section{Introduction}

Over the course of human history, people have developed many interconnected physical, biological, psychological, and social worlds. These ideas have enabled successive generations to achieve an increasingly comprehension and reliable understanding of the human species and its environment. The means used to develop these ideas are particular ways of observing, thinking, experimenting, and validating. These ways represent a fundamental aspect of the nature of science and reflect how science tends to differ from other modes of knowing.

According to McLelland 2006, Science is a methodical approach to studying the natural world. Science asks basic questions, such as how does the world work? How did the world come to be? What was the world like in the past, what is it like now, and what will it be like in the future? These and many more questions are answered using observing, testing, and interpretation through logic.

Most scientists would not say that science leads to an understanding of the truth. Science is a determination of what is most likely to be correct at the current time with the evidence at our disposal. Scientific explanations can be inferred from confirmable data only, and observations and experiment must be reproducible and verifiable by other individuals. (McLelland, 2006)

In other words, good science is based on information that can be measured or seen and verified by other scientists.

It is in a bid to understand what research/scientific proposal is all about that the paper tries to elaborate and throw more convictions on. What is the nature of scientific research proposal? Its role and the scope is the hall mark of this write up.

\section{The Nature Of Scientific Reseacrh Proposal}

In the Nature of Science and the Scientific Method by McLelland, 2006, the scientific method, it could be said is a way of learning or a process of using comparative critical thinking. Things that are not testable or falsifiable in some scientific or mathematical way, now or in the future, are not considered science. Falsifiability is the principle that a preposition or theory cannot be scientific if it does not admit the possibility of being shown false. Science takes the whole universe and any and all phenomena in the natural world under its purview, limited only by what is feasible to study given our current physical and fiscal limitations. Any thing that cannot be observed or measured or shown to be false is not amenable to scientific investigation. Explanations that cannot be based on empirical evidence are not a part of science (National Academy of sciences, 1998).

According to Nickels, 1998, scientific knowledge is based on the following assumptions which are;

- The world is REAL; it exists apart from our sensory perception of it.

- Humans can accurately perceive and attempt to understand the physical universe.

- Natural processes are sufficient to explain or account for natural phenomena or events. In other words, scientists must explain the natural in terms of the natural (and not the supernatural, which, lacking any 
independent evidence, is not falsifiable and therefore not science), although humans may not currently recognize what those processes are.

- By the nature of human mental processing, rooted in previous experiences, our perceptions may be inaccurate or biased.

- Scientific explanations are limited. Scientific knowledge is necessarily contingent knowledge rather than absolute, and therefore must be evaluated and assessed, and is subject to modification in light of new evidence. It is impossible to know if we have thought of every possible alternative explanation or every variable, and technology may be limited.

- Scientific explanations are probabilistic. The statistical view of nature is evident implicitly or explicitly when stating scientific predictions of phenomena or explaining the likelihood of events in actual situations.

As stated in the National Science Education Standards for the Nature of Science:

Scientists formulate and test their explanations of nature using observation, experiments, and theoretical and mathematical models. Although all scientific ideas are tentative and subject to change and improvement in principle, for most major ideas in science, there is much experimental and observational confirmation. Those ideas are not likely to change greatly in the future. Scientists do and have changed their ideas about nature when they encounter new experimental evidence that does not match their existing explanations. (NSES, 1996, p. 171)

Understanding of the nature of science - the goals, values and assumptions inherent in the development and interpretation of scientific knowledge (Lederman, 1992) - has been an objective of science instruction since at least the turn of the last century. It is regarded in contemporary documents as a fundamental attribute of science literacy and a defense against unquestioning acceptance of pseudoscience and of reported research. Knowledge of the nature of science can enable individuals to make more informed decisions with respect to scientifically based issues; promote student in-depth understanding of "traditional" science subject matter, and help them distinguish science from other ways of knowing.

Rene Descartes established the framework of the scientific method in 1619, and his first step is seen as a guiding principle for many in the field of science today;

.....never to accept anything for true which I did not clearly know to be such; that is to say, carefully to avoid precipitancy and prejudice, and to compromise nothing more in my judgment than what was presented to my mind so clearly and distinctly as to exclude all ground of methodic doubt. (Discours de la method 1637, section 1, 120). ( McLelland, 2006)

McLelland, 2006 went further to state that by stocking to certain accepted "rules of reasoning" scientific method helps to minimize influence on result by personal, social;, or unreasonable influences. Thus, science is seen as a pathway to study phenomena in the world, based upon reproducibly testable and verifiable evidence.

This pathway may take different forms; in fact, creative flexibility is essential to scientific thinking, so there is no single method that all scientist use, but each must ultimately have a conclusion that is testable and falsifiable, otherwise, it is not science (Christine, 2012). The scientific method in actuality isn't a set sequence of procedures that must happen, although it is sometimes presented as such. Some descriptions actually list and number three to fourteen procedural steps. No matter how many steps it has or what they cover, the scientific method does contain elements that are applicable to most experimental sciences. Scientific method refers to a body of techniques for investigating phenomena, acquiring new knowledge, or correcting and integrating previous knowledge. To be termed scientific, a method of inquiry must be based on gathering empirical and measurable evidence subject to specific principles of reasoning. (McLelland, 2006)

Research simply implies an examination, inquiry, investigation or an experiment which is aimed at discovering facts (Egbule et al 1998). Research is the discovering and interpretation of facts that is known to exist. It is the revision of accepted theories or laws in the light of new forms or developments. Nwankwo (1984) defined research as "a diligent and systematic investigation intended to provide acceptable answers to questions by following logically designed procedure". According to Whawo (1992) research may be explained as a process of searching for a solution to an identified problem. Such problems generate the desire to critically examine it so that solution can be synthesized. Therefore, research could be said to be a systematic process of problem analysis in an effort to find solution to such problems. All researches are characterized with a central problem that requires scientific solution through empirical investigation research undertaking calls for objectivity through the application of standardized, valid and reliable measurement device which helps to guide against personal subjectivity (Egbule et al 1998).

The Oxford English Dictionary says that scientific method " is" a method or procedure that has itemized natural science since the $17^{\text {th }}$ century, consisting in systematic observation, measurement, and experiment, and the formulation, testing, and modification of hypothesis.

Science inquiry is generally intended to be as objective as possible, to reduce biased interpretations of results. Another basic expectation is to document, archive and share all data and methodology so they are 
available for careful scrutiny by other scientists, giving them the opportunity to verify results by attempting to reproduce them. This practice allows statistical measures of the reliability of these data to be established.

The main characteristic which differentiates a scientific methods of investigation from other methods of acquiring knowledge of the world is that scientists seek to let reality speak for itself, supporting a theory when a theory's predictions are confirmed and challenging a theory when its predictions prove false. Procedure may vary from one field of investigation to another, identifiable feature distinguish scientific investigation from other methods of acquiring knowledge. Scientific researchers propose hypotheses as explanations of phenomena, and design experimental studies to test these hypotheses via predictions which can be derived from them. These steps must be repeatable, to guard against mistake or confusion in any particular experimenter. Theories that encompass wider domains of inquiry may bind many independently derived hypotheses together in a coherent supportive structure. Theories in turn, may help form new hypothesis or place groups of hypotheses into context.

Scientific methodology has been practiced in some form for at least one thousand years, and is the process by which science is carried out. Because science builds on previous knowledge, it consistently improves its understanding of the world; scientific method improves itself in the same way, meaning that it gradually become more effective at generating new knowledge. For example, the concept of falsification (first proposed in 1934) reduces confirmation bias by formalizing the attempt to disprove hypotheses rather then prove them (Karl R.P 1963).

The overall process involves making conjectures (hypothesis) deriving predictions from them as logical consequences, and then carrying out experiments based on these prediction to determine whether the original conjectures was correct through the scientific method is often presented as a fixed sequence of steps. They are better considered as general principles (Gauch 112003 ). Not all steps take place in every scientific inquiry (or to the same degree), and not always in the same order. As noted by William Whewell (1794-1866), "invention, sagacity, (and) genius are required at every step.

The important goal of scientific investigation is to obtain knowledge in the form of testable and verifiable explanations that can predict the results of future explanations. It enables scientists to gain an understanding of reality, and later use that knowledge to intervenes in its causal mechanisms. The better an explanation is at making predictions, the more useful it is, and the more likely it is to be correct. The most successful explanations, which explain and make accurate predictions in a wide range of circumstances, are called scientific theories (Wikipedia. Org, 2012).

Most experimental results do not result in large change in human understanding. Improvements in theoretical scientific understanding; is usually the result of a gradual synthesis of the results of different experiments by various researchers, across different domains of science.

(Stanovich, 2007). Scientific models vary in the extent to which they have been experimentally tested and how long, and in their acceptance in the scientific community. In general, explanations become accepted by a scientific community as evidence in favor is presented and as presumptions that are inconsistent with the evidence are falsified.

New Scientific ideas are subject to skepticisms, especially if they challenge well- established scientific ideas. One generally accepted by the scientific community, scientific knowledge is durable. Therefore, it is reasonable to have confidence in scientific knowledge while still recognizing that new evidence may result in changes in the future. Related to the tentative nature of science is the idea that regardless of the amount of empirical evidence supporting a scientific idea (even a law), it is impossible to prove that the idea holds for every instance and under every condition. Einstein's modifications to the well -established Newtonian laws are a classic case in point. Thus, "Truth" in the absolute sense, lies outside the scope of science (Popper 1988). Scientific laws do not provide absolutely true generalization, rather, they hold under very specific conditions (Cartwright, 1883, 1988). Scientific laws are our best attempts to describe patterns and principals observed in the natural world. As human constructs, these laws should not be viewed as infallible. Rather, they provide useful generalization for describing and predicting behavior under specific circumstances.

According to Best (1989), research is a systematic activity that is directed towards discovery and the development of an organized body of knowledge. While Whawo (1992) described research as a process of searching for a solution to an identified problem. In his opinion such a problem necessitates the researcher's desire to formulate hypothesis, generate data, and employ critical analysis of data before reaching conclusion. In effect, whatever conclusion is reached becomes a contribution to knowledge.

Basically, research is a systematic procedure of problem solving through the application of the scientific method of inquiry (Oganwu pg1-2 2004). Scientific method according to Kerlinger (1973) is "Systematic, controlled, empirical and critical investigation of hypothetical propositions about presumed relations among natural phenomena". This definition is inclined towards the deductive mode. In another development Scientific method is a non-authoritarian democratic, self-correcting, intellectual and moral authority by which man may give his actions. 
Scientific explanations must be logically consistent, abide by rules of evidence, be open to questions and modification and be consistent with current scientific knowledge (NRC, 1996). Inquiry is at the heart of scientific enterprise, and as such, demands a prominent position in scientific investigation. Scientific inquiry refers to the ways in which scientists study the natural world and propose explanations based on evidence derived from their work. McLelland, 2006 asserted that equally important is an understanding of the nature of science" or science as a way of knowing." The nature of science has been defined in a variety of ways, and these definitions are hotly debated among philosophers and sociologists of the science (Lederman, 2007). One assumption central to the scientific enterprise is that the universe is knowable (Lederman, 1992).

\section{SCOPE OF RESEARCH PROPOSAL}

Scope of research proposal sets the boundary of a research. It gives an overview of the limit ant extent of a research. The scope takes into cognizance the direction to follow and the areas that need to be covered. It is arranged in such a way that every singular action and areas to be covered are well outlined for easy follow up.

The scope of a research proposal covers areas such as stated by Osaze, 2011 as follows:

- Immediate purposes of the research. This should be a statement of the research question or hypotheses to be tested and should be quite clear and precise

- Theoretical foundations and conceptual framework should be an indication of the theoretical model upon which the study will be based.

- Relation to other research: This is a statement of the study and how it would relate to other published or ongoing theoretical or empirical work in the same field. Would it replicate, disconfirm, confirm or add to existing studies?

- Research design: This should describe the entities or phenomena/variables to be studied, the logic underlying the investigative procedures; data collection procedures; measurement techniques and statistical tools and techniques to be used

- Implementation of the design; How does the researcher hope to gain access to the research situation or gain the co-operation of entities to be studied.

- Overall schedule or logical flow chart for the study: There should be specific dates and deadlines for each stage of the research work from conception to submission which the researcher most attempt to stick to religiously. It disciplines the researcher in terms of time keeping.

- Resources for the study: How much money and time would be required to complete the study. What plans are there to obtain these resources without any hitch that might jeopardize the research?

- Contingency plans: Every research is bound to experience problems at some stage. What are the probable problems that may arise? What are the plans that the researcher has developed for the project to be viable if initial plans fail at a critical stage?

- Possible application of the results of the research: Who are likely to be the end users of the results of the research? Indicate, Government, Educational Institute, other researchers.

- Directions for further research: What are the other areas not covered in the original scope of the study but uncovered during the research that require further investigation in subsequent research?

Summarily, the scope of a research proposal in scientific investigation covers areas such as Statement of the research problem, Aims and objective of the research, Review of related literatures, Conceptual framework for the study, and the methodology of data collection, presentation, and analysis. It also entails hypotheses formulations, testing, verification and confirmation or rejection.

\section{ROLE OF RESEARCH PROPOSAL IN SCIENTIFIC INVESTIGATIONS}

A good research proposal serves the following roles in scientific investigations

1. It gives the research a graphic and mental image of how the study will be done, mode of gathering the pertinent data and the analysis of data

2. The research design, no doubt, provides guides to the research in his efforts to generate required data for the study

3. It facilitates the proper delineations of the scope of the study

4. It is the research design that allows the researcher to be acquainted with the likely problems in the execution of his study

5. It enhances development in fields of science, technology, education, politics, medicine, management, social sciences and the likes.

6. It exposes learners or trainers to various skills in the acquisition of critical thinking, rational reasoning, logical analysis as well as deductive and inductive inferences

7. It is aimed at generating hypotheses, principles, laws and theories

8. It stands on an empirical evidence 
9. It gives room to accurate observation of information collected through the usage of standardized, reliable and valid measuring tool or instrument.

10. It aimed at offering solutions to scientific enquiries

11. It helps in validating and updating some form of knowledge for the purpose of innovations

12. Research proposal provides trainees and practitioners with special skills in problem solving.

\section{Conclusion}

Percy W. Bridgman, author of Reflections of a Physicist in 1955 and winner of the 1946 Nobel Prize in physics, as cited in perhaps most clearly states in "On Scientific Method" how the use of the sited in the work of McLelland, 2006, Scientific method by scientists does not often follow a set formula or recipe, nor should it, since that may stifle human innovation and creativity, often necessary in producing new and revolutionary hypotheses:

Scientific method is what working scientists do, not what other people or even they themselves may say about it. No working scientist, when he plans an experiment in the laboratory, asks himself whether he is being properly scientific, nor is he interested in whatever method he may be using as method. When the scientist ventures to criticize the work of his fellow scientist, as is not uncommon, he does not base his criticism on such glittering generalities as failure to follow the "scientific method," but his criticism is specific, based on some feature characteristic of the particular situation. The working scientist is always too much concerned with getting down to brass tacks to be willing to spend his time on generalities. (Percy, 1955)

Percy went further to say that to the scientist himself all this steps of scientific method appears obvious and trite. What appears to him as the essence of the situation is that he is not consciously following any prescribed course of action, but feels complete freedom in utilizing any method or device whatever, which in the particular situation before him seems likely to yield the correct answer. (Percy, 1955)

Science is more than a body of knowledge and way of developing and validating that knowledge. Science is a social activity that reflects human values, including curiosity, creativity, integrity, and skepticism.

\section{References}

[1]. Best, J.N (1981). Research in Education, New Jersey Prentice - Hall Inc.

[2]. Cartwright, N. (1983).How the laws of physics lie. Oxford; Oxford University Press

[3]. Cartwright, N. (1988).The truth doesn't explain much. In E.D. Klemke, R. Hollnger and D. Kline (Eds) .Introductory readings on the philosophy of (pp129-136). Buffalo, New York; Prometheus Books

[4]. Gauch, Hugh G.Jr (2003), Scientific method in practice (http; //books. google.Com/?Id=ivkugqNG9dAC).Cambridge University Press. ISBN 0-521-01708-4,http://books.Google.Com/? Id=iVkugqNG9dAC

[5]. http://en. Wikipedia or/wiki/scientific-method (2012). Scientific_Method. From Wikipedia, the free encyclopedia, $05 / 19 / 2012$

[6]. Karl R. Popper (1963), 'The logic of scientific Discovery'. The Logic of Scientific Discovery (http://www. Consmopolitan university.ac/library/LogicofscientificDiscovery Popper1959.pdf) pp 17-20,249-252.

[7]. Kerlinger, F.N (1973) formulations of Behavioural Research $\left(2^{\text {nd }}\right.$ ed) New $\quad$ York: Rinehart and winthron Incs of Behavioural Research $\left(2^{\text {nd }}\right.$ ed) New York: Rinehart And Winthron Inc

[8]. Lederman, N.G (1992). Student's and teaching conceptions of the Nature of science: A review of the research, Journal Of Research in Science Teaching.

[9]. Lederman, N.G. (2007), Nature of Science: past present, and future. In S.K Abell and N.G. Lederman (Editors) Handbook of research on science education. Mahwah, N.J. Lawrence Erlbaum Associates.

[10]. McLelland, Christine V., "The Nature of Science and the Scientific Method,"The Geological Society of America, August 2006, http://www.geosociety.org/educate/NatureScience.pdf] [512 KB PDF

[11]. National Academy of Sciences, Teaching about Evolution and the Nature of science, working Group on Teaching Evolution, 1998

[12]. Natural Research Council (1996). National science education Standards, Washington, DC: National Academic Press.

[13]. NSTA Press, Teaching about evolution and nature of science. http://www.nsta.org.ISBN13:978-0-30906-364- 7, 1998

[14]. Oganwu, P.1 (2004) Research methods for Beginners; Theory and Practice. COEWA Publisher Warri.

[15]. Osaze, B.E (2011), Guidelines for writing Theses and Dissertations. AMBIK. PRESS, Benin-City.

[16]. Popper, K.R (1988) science: conjectures and refutations. In E.D Klemke, R Hollinger, and A.D Kline (Eds), introductory readings on the philosophy of science (pp 129-136).Buffalo. New York:Prometheus Books.

[17]. Percy N.B (1955) "On scientific Method" in reflections of a physicist, 1950, from collected Experimental papers,7 vol.:1964

[18]. Stanovich, Keith E (2007). How to Think Straight about Psychology. Boston: Pearson Education.pg 123

[19]. Whawo, D.D (1992): Basic Educational Research and Statistics, Benin -City: Saming O Publishers (Nig) Ltd 